\title{
Crowdfunding. Una nueva opción para la financiación de proyectos en salud
}

\author{
Crowdfunding. A new option for funding health projects
}

\author{
Dra. Paula Otero ${ }^{a}$
}

http:/ /dx.doi.org/10.5546/aap.2015.154

\section{INTRODUCCIÓN \\ Definición}

La financiación colectiva de proyectos en la web por medio de plataformas virtuales se conoce como crowdfunding. Otras denominaciones que se emplean son financiación en masa, micro mecenazgo, o micro patronazgo.

En la actualidad se está afianzando como una forma de obtener fondos para financiar proyectos que no pueden acceder a la forma de financiación habitual como préstamos, subsidios y becas, ya que por su carácter o tipología no encajan ni en los requisitos de apoyo de entidades públicas ni llaman la atención de la iniciativa privada.

El crowdfunding tiene como objetivo que cualquier persona que desee llevar adelante un proyecto pueda conseguir la financiación para su lanzamiento con la ayuda de una gran cantidad de personas que aportan micro-donaciones. ${ }^{1}$

Esta modalidad se ha iniciado en Estados Unidos pero ya ha avanzado en Europa y lentamente se está introduciendo en Latinoamérica. A nivel mundial, durante el año 2013, el crowdfunding ha logrado financiar más de 1200000 proyectos sin que intervenga financiación estatal o gubernamental.

El mecanismo de crowdfunding también está relacionado con las redes sociales, donde los consumidores participan activamente en las comunidades en línea para compartir información, conocimientos y sugerencias acerca de una nueva iniciativa y/o marca.

La participación activa de los usuarios hace que sean el eje del éxito de varios proyectos ya que ellos determinan qué iniciativa desean seleccionar para apoyar y proporcionar su apoyo financiero. ${ }^{2}$

\section{Tipos de crowdfunding}

Existen diferentes modalidades en función del tipo de intercambio entre los financiadores y los beneficiarios con el aporte para el proyecto por lo que no todo crowdfunding puede considerarse una modalidad pura de mecenazgo. ${ }^{2-4}$

- Donación (donation-based crowdfunding): esta metodología en general se utiliza para proyectos solidarios donde el monto recibido no recibe ninguna contrapartida como moneda de cambio. El único incentivo es el retorno social; los colaboradores solo apuntan a la satisfacción de ver qué proyecto puede ser realizado por lo que su motivación es intrínseca. Este tipo es ampliamente utilizado por organizaciones sin fines de lucro.

- Recompensa (reward-based crowdfunding): es utilizada para proyectos donde el financiador reciba una retribución como premio, que puede ser desde una mención a través de las redes sociales o un objeto que represente su donación. Este tipo puede ser utilizado por cualquier tipo de emprendimiento o proyecto y es una metodología muy adoptada por varias iniciativas en la actualidad.

- Inversión (equity-based crowdfunding): en este caso los financiadores reciben acciones o participación en las ganancias que el proyecto obtenga o un producto o servicio como forma de 
reconocimiento. Los inversores pueden recibir el producto o servicio final completo o con un descuento del precio de venta que tendrá para el público en general. Este tipo es utilizado para el desarrollo de nuevas tecnologías como pueden ser determinaciones diagnósticas de patologías poco frecuentes.

- Préstamo (lending-based crowdfunding): se acuerda entre las partes que la financiación será un préstamo con un interés determinado. En este caso el donante se considera un inversor que desea un rendimiento financiero, por lo que se posiciona como una alternativa atractiva en lugar de los créditos tradicionales. Sin embargo en el campo de la investigación en salud puede no ser de sencilla aplicación.

El sistema de recompensas se está posicionando como la metodología más difundida y es utilizada con frecuencia para las empresas creativas o que ofrecen productos de consumo pequeños, donde la pre-financiación básica para la producción de la iniciativa está ligada a una prueba de la demanda inicial, ya que si un número suficiente de personas ayudan al proyecto, este tendrá la validación, así como el pre-financiamiento para sus actividades. ${ }^{5}$

\section{Metodología del crowdfunding}

La metodología del crowdfunding abarca el proceso desde la publicación del proyecto hasta su difusión con el objeto de recolectar el monto de dinero propuesto por la iniciativa.

En una campaña de crowdfunding existen tres actores importantes en su proceso de planeamiento: el que busca y necesita la financiación para la idea o proyecto, el financiador y la plataforma que permite la interacción facilitando la comunicación entre los principales actores.

Las plataformas para crowdfunding necesitan que se defina un tiempo establecido para la recolección de fondos, el monto de dinero necesario y se establezca (si corresponde) el sistema de recompensas en función del monto aportado o el compromiso de devolver el dinero en caso que no se pueda recolectar el monto total para la propuesta. Estas plataformas ofrecen las herramientas para la realización de transacciones de las donaciones para el pago con tarjeta de crédito u otras formas de pago como transferencia bancaria o PayPal.

Una vez publicado se debe iniciar la difusión por todos los medios posibles (redes sociales, blogs, portales web, correo electrónico, etc.).
Por este motivo es que las redes sociales pueden ayudar a vitalizar la propuesta, que de otra manera solo quedaría entre familiares y amigos.

\section{El cuidado de la salud en la época actual}

En los últimos años hemos sido testigos del cambio transformador que está teniendo la práctica de la medicina en lo que respecta a cómo se aplica la ciencia, la tecnología, la personalización, la movilidad y los medios de comunicación social.

En esta situación se amplía la brecha entre los países con mayores recursos frente a los países de menores recursos en cómo se desarrolla, brinda y se gestionan los aspectos de la salud y la enfermedad a nivel de salud pública.

Por otro lado la medicina convencional se comporta con un enfoque reactivo, en el que las enfermedades son tratadas una vez que se presentan. Es por eso que para que el cuidado de la salud haga foco en la prevención y no tome las enfermedades una vez instaladas, se necesita una transformación del modelo reactivo a proactivo que requiere de la tecnología y la participación de la población en igual medida. Por otro lado la transformación hacia la medicina personalizada, que a su vez sea preventiva y participativa puede exigir un aumento en el gasto económico, sobre un sistema de salud que ya es deficiente en su financiación.

El crowdfunding se está aplicando para el desarrollo de proyectos con foco en temas sociales. La asistencia sanitaria debe ser considerada un tema de impacto social, como es la ayuda a los países en desarrollo, la disminución de la pobreza y la difusión de las nuevas tecnologías. ${ }^{6}$

Crowdfunding en salud... ¿dónde está el nicho?

A pesar de que el crowdfunding ha demostrado en los últimos años ser de utilidad para financiar proyectos artísticos, tecnológicos y otros emprendimientos, todavía no ha sido abarcado en profundidad por la comunidad dedicada al cuidado de la salud, tanto desde el punto de vista de la investigación como el asistencial. Una de las razones puede ser que el crowdfunding requiere de una fuerte presencia en línea, y que el ideólogo de un proyecto sea dinámico y conocedor de las redes sociales, situación que en el ámbito académico no ha sido muy común, ya sea por falta de tiempo o incentivos para su desarrollo. ${ }^{7}$

En general la medicina asistencial y la investigación hacen foco sobre las patologías que afectan a una gran cantidad de población 
en los países desarrollados. Sin embargo existen enfermedades que pueden considerarse "huérfanas" ya que no son el objetivo principal en el cuidado de la salud. Por ejemplo, las enfermedades infectocontagiosas que son endémicas en países de menores recursos, como el dengue, el paludismo, la enfermedad de Chagas y ahora el Ébola no poseen una vacuna o tratamiento probado. Por otro lado existen más de 7000 enfermedades de origen genético que a pesar de que afectan más de 350 millones de personas en todo el mundo, no se estudia la secuencia de sus genes en profundidad por su baja incidencia. Estos dos ejemplos de temas no tomados por la medicina convencional han sido foco para la aplicación de crowdfunding.

Existen sitios en los EE.UU. dedicados exclusivamente a estos temas, que están centrados en cómo ayudar a los pacientes en forma directa, tales como GiveForward, GoFundMe y YouCaring. ${ }^{8}$

En la Argentina el crowdfunding no ha despegado aún. Una de las principales iniciativas que hoy tiene presencia en la web es Idea.me (http:/ /idea.me/) que comenzó a funcionar en agosto de 2011 y ha conseguido financiar casi 200 proyectos que corresponden al 30\% de los presentados no solo de Argentina, sino también de México, Brasil, Chile y Uruguay.

El sitio promueve dos métodos de recaudación, por un lado el "Todo o Nada" donde se debe alcanzar el 100\% del objetivo económico antes de que finalice el período de recaudación. De no poder llegar a la meta el dinero es devuelto a los colaboradores. Por otro lado, está el "Todo Suma" donde a pesar de que no se llegue al objetivo se puede iniciar el proyecto y entregar las recompensas a sus colaboradores. Cada proyecto debe contemplar un plan alternativo de uso del total recaudado para comunicar tanto a Idea.me como a los colaboradores del proyecto.

A otro nivel, con foco en recaudaciones solidarias, se encuentra Nobleza Obliga (http:/ / www.noblezaobliga.com) que tiene como objetivo facilitar a cualquier persona la recaudación de fondos en forma solidaria para hacer realidad su causa y generar un impacto positivo en su comunidad.

\section{Crowdfunding para financiar la investigación y la innovación en salud}

A nivel mundial se ha visto que ante situaciones de crisis económicas se dificulta el acceso al crédito y la financiación para realizar tanto investigación básica como clínica.
Es por este motivo que los investigadores de diferentes países han adoptado la metodología del crowdfunding para poder financiar proyectos de investigación.

Se ha descripto que existen tres factores fundamentales que pueden ayudar a que el crowdfunding sea una opción sustentable para lograr financiación destinada a la investigación: ${ }^{9}$

- Una creciente necesidad de financiación para la investigación y el desarrollo.

- La posibilidad de dinamizar los sistemas y protocolos de investigación.

- Buscar y explotar el potencial de este nuevo canal de financiación para el apoyo a las ciencias.

Aunque estas campañas de financiación multitudinarias no pueden ser consideradas en reemplazo de las becas o subsidios de investigación, ya que proporcionan pequeñas cantidades de dinero en comparación, pueden servir como puntapié inicial o para el desarrollo de estudios piloto. El hecho de que este tipo de proyectos puedan ser difundidos de manera masiva, muchas veces genera la atención de posibles financiadores que brinden mayor aporte económico. ${ }^{9,10}$

Existen diferentes experiencias a nivel mundial que han utilizado el crowdfunding como punto de inicio para su financiación.

En la experiencia descripta por Cameron y col. ${ }^{11}$ se describen tres casos de éxito en la utilización de crowdfunding para financiar la investigación en salud. Genome Liberty utilizó la plataforma Rockethub para poder crear una empresa que brinda análisis de secuenciación e interpretación genómica directamente a pacientes a un menor costo trabajando sobre la legislación de patentes que generaba un monopolio en el análisis de genes. El caso de éxito fue para el gen BRCA1 del cáncer de mama cuya patente pertenecía de manera exclusiva a la empresa Myriad Genetics. Cada paciente debía pagar US $\$ 3000$ por cada estudio, mientras que en otros laboratorios existía tecnología para poder realizarlo por US\$200. La contribución obtenida fue de US\$10.000 y les ayudó al desarrollo de marcadores genéticos que estaban disponibles para los pacientes a un precio accesible. Esta campaña ha motivado el desarrollo de otras iniciativas con similar éxito como el Rare Genomics que brinda ayuda a niños con enfermedades genéticas no conocidas, para que se pueda realizar la secuenciación de sus genes. ${ }^{12}$

Otra campaña fue la de PathoMap, publicada 
en la plataforma Indiegogo, que tenía como objetivo analizar los microorganismos presentes en las superficies comunes de la calle como la baranda del metro o un banco de plaza en la ciudad de Nueva York, con el objeto de prevenir enfermedades infectocontagiosas enviando alertas a los teléfonos móviles personales. El objetivo era recaudar US $\$ 10.000$, sin embargo la campaña solo consiguió el 3\%; a pesar de la baja tasa de respuesta, sirvió como difusión para que otras empresas se interesaran en la propuesta con lo que se logró una financiación total de US\$12.000. En estos ejemplos podemos ver cómo temas de investigación innovadores y de patologías habituales pueden ser de interés para que las personas donen su dinero.

\section{CONCLUSIÓN}

El crowdfunding se está posicionando a nivel mundial como una novedosa fuente de microfinanciación para proyectos personales e institucionales donde los fondos por los medios tradicionales no llegan. El cuidado de la salud y la investigación sanitaria no son ajenos a esta tendencia.

Una de sus principales características es que facilita mediante la financiación colectiva, que cualquier persona o institución que desee llevar adelante un proyecto (empresarial, cultural, social o de salud) pueda conseguir los fondos que muchas veces no es posible obtener utilizando los medios tradicionales. Tiene como valor agregado la promoción de la colaboración en aquellos que comparten objetivos comunes y la posibilidad de masificar proyectos que de otra manera no serían del todo difundidos.

\section{REFERENCIAS}

1. Gerber EM, Hui JS, Kuo P-Y. Crowdfunding: why people are motivated to post and fund projects on crowdfunding platforms. Proceedings of the International Workshop on Design, Influence, and Social Technologies: Techniques, Impacts and Ethics; 2012; Seattle, Washington.

2. Ordanini A, Miceli L, Pizzetti M, Parasuraman A. Crowdfunding: transforming customers into investors through innovative service platforms. Journal of Service Management 2011;22(4):443-70.

3. Informe de la encuesta de la Asociación Española de Crowdfunding sobre las plataformas españolas de crowdfunding 2014. AsociaciónEspañola deCrowdfunding; 2014. [Consulta: 14 de octubre de 2014]. Disponible en: http://web.spaincrowdfunding.org/wp-content/ uploads / 2014/06/INFORME-DE-LA-ENCUESTADE-LA-ASOCIACI\%C3\%93N-ESPA \%C3\%91OLA-DECROWDFUNDING.pdf

4. MollickE. The dynamics of crowdfunding: An exploratory study. J Bus Venturing 2014;29(1):1-16.

5. De Buysere K, Gajda O, Kleverlaan R, Marom D, et al. A framework for European crowdfunding. European Crowdfunding Network; 2012. [Consulta: 14 de octubre de 2014]. Disponible en: http://www. europecrowdfunding.org/files/2013/06/FRAMEWORK_ EU_CROWDFUNDING.pdf

6. Nimita L, Carol IB. The modern social contract between the patient, the healthcare provider, and digital medicine. J Socialomics 2014;3(1):105.

7. Perlstein EO. Anatomy of the Crowd4Discovery crowdfunding campaign. Springerplus 2013;2:560.

8. Sisler J. Crowdfunding for medical expenses. CMAJ 2012;184(2):E123-4.

9. Crowdfunding para la ciencia y la investigación. Revista Vorticex [Internet]. 2013;(1). [Consulta: 14 de octubre de 2014]. Disponible en: http://www.vorticex.org/revista/ crowdfunding-id/.

10. Kaplan K. Crowd-funding: cash on demand. Nature 2013;497(7447):147-9.

11. Cameron P, Corne DW, Mason CE, Rosenfeld J. Crowdfunding genomics and bioinformatics. Genome Biol 2013;14(9):134.

12. Barclay E. The sick turn to crowd funding to pay medical bills. NPR; 2012. [Consulta: 1 de agosto de 2014]. Disponible en: http://www.npr.org/blogs/ health / 2012 / 10/23/163489063/the-sick-turn-tocrowdfunding-to-pay-medical-bills 